\title{
Industrial Engineering Outreach to K-12 Community
}

\section{Mr. Anuj Mittal, Iowa State University}

Anuj Mittal is a PhD Candidate in Industrial and Manufacturing Systems Engineering at Iowa State University. His research interests include agent-based modeling and discrete-event simulation and their applications in sustainable sociotechnical systems. He is currently a NSF-Trinect Engineering Fellow, and is working with cooperating teachers and student teachers at Des Moines Public Schools to help improve STEM education in an elementary school classroom. He is actively involved in developing and deploying several Industrial Engineering outreach activities with the K-12 community at Iowa State University. He obtained his B.S. in Electrical Engineering from University of Delhi, India and a M.S. in Industrial Engineering from Iowa State University. He has worked as an engineer for Whirlpool Corporation, Amana and Doosan Power Systems India.

\section{Prof. Sriram Sundararajan, Iowa State University}

Sriram Sundararajan is a Professor of Mechanical Engineering and serves as the Associate Dean for Academic Affairs in the College of Engineering at Iowa State University. His research areas encompass multiscale tribology (friction, lubrication and wear) and engineering education. He has authored over 70 articles in peer-reviewed journals and conference proceedings and two invited book chapters. He is a Fellow of the American Society of Mechanical Engineers (ASME) and serves as an ABET program evaluator. Sriram is a steering committee member for the International Conference on Wear of Materials and an executive committee member of the Mechanical Engineering Division of the American Society of Engineering Education (ASEE). He serves as their delegate on the ASEE diversity committee and also on the ASME Diversity and Inclusion Strategic Committee. He received his B.E. degree in Mechanical Engineering from The Birla Institute of Technology and Science, Pilani (India) followed by M.S. and PhD degrees in Mechanical Engineering from The Ohio State University, Columbus, Ohio.

\section{Dr. D. Raj Raman, Iowa State University}

Raj Raman is Morrill Professor of Agricultural and Biosystems Engineering (ABE) Department at Iowa State University, where he is also University Education Program Director and Testbed Champion for the NSF Engineering Research Center for Biorenewable Chemicals (CBiRC). He is a licensed Professional Engineer who earned his BS in Electrical Engineering from the Rochester Institute of Technology and his $\mathrm{PhD}$ in Agricultural and Biological Engineering from Cornell University. Prior to coming to Iowa State in 2006, he was a faculty member at the University of Tennessee for over twelve years.

Raman enjoys teaching and has taught courses including freshmen engineering (mechanics and computer programming - to classes ranging in size from 20 to 500+), sophomore and junior level courses on mass and energy balance applications to biological systems engineering, numerical methods, electric power and electronics for technology students, senior design, as well as a long-standing residential/online graduate course on the fundamentals of biorenewable resources and technology. He believes well trained, curious, thoughtful people are crucial to a university's research effort, and similarly to the function and survival of society. For this reason, the overarching goal of his teaching is to impart the core content needed by the students, and to do so while encouraging inquisition and higher levels of thought. He has secured competitive funds to support his teaching efforts - from university, industry, and federal sources - and for his efforts has received departmental, college, and national teaching honors including the MasseyFerguson Gold Medal Award given by the American Society of Agricultural Engineers.

Raman chairs the ABE Engineering Curriculum Committee and in that role oversaw the successful 2012 ABET accreditation visit for both the Agricultural Engineering (AE) and Biological Systems Engineering (BSE) degree programs. Upon arriving at ISU in 2006, he led the development of the BSE program, a program that enrolls over 100 students. In his role as Pyrone Testbed Champion for CBiRC, Raman and his students have developed early-stage technoeconomic models of bioprocessing systems. His graduate students have gone on to faculty positions at Purdue and the University of Georgia, and to engineering leadership positions at companies including Cargill, Nestle, and Merck. 


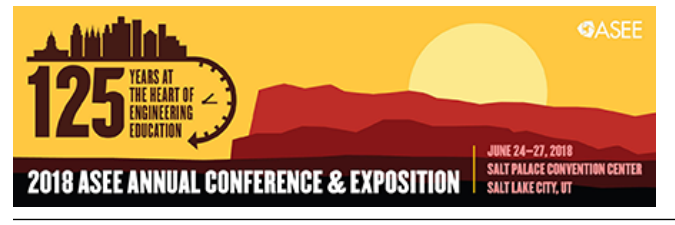

Paper ID \#21669

\section{Dr. Caroline C. Krejci, University of Texas at Arlington}

Dr. Caroline Krejci is an Assistant Professor of Industrial, Manufacturing, and Systems Engineering at The University of Texas at Arlington. She holds a Ph.D. in Industrial Engineering from the University of Washington. Her research is focused on the development of quantitative methodologies for the analysis and sustainable management of sociotechnical systems, including supply networks and production systems. Her email address is caroline.krejci@uta.edu. 


\section{Industrial Engineering Outreach to the K-12 Community}

\section{Introduction}

Despite the ubiquity of industrial engineers in the workplace, the K-12 community is relatively unaware of this engineering discipline. Previous research has demonstrated that the identity of industrial engineering (IE) is ambiguous, and many K-12 educators are unaware that such a discipline even exists [1]. As a result, few high school students pursue IE as a career option. Recent engineering enrollment data from Iowa State University provides empirical evidence of this lack of awareness. As illustrated in Figure 1, the percentage of undeclared engineering students choosing to major in IE after arriving on campus is much higher than those choosing IE directly upon arrival on campus. In contrast, the values of these two metrics tend to be similar for more familiar disciplines, such as mechanical and electrical engineering.

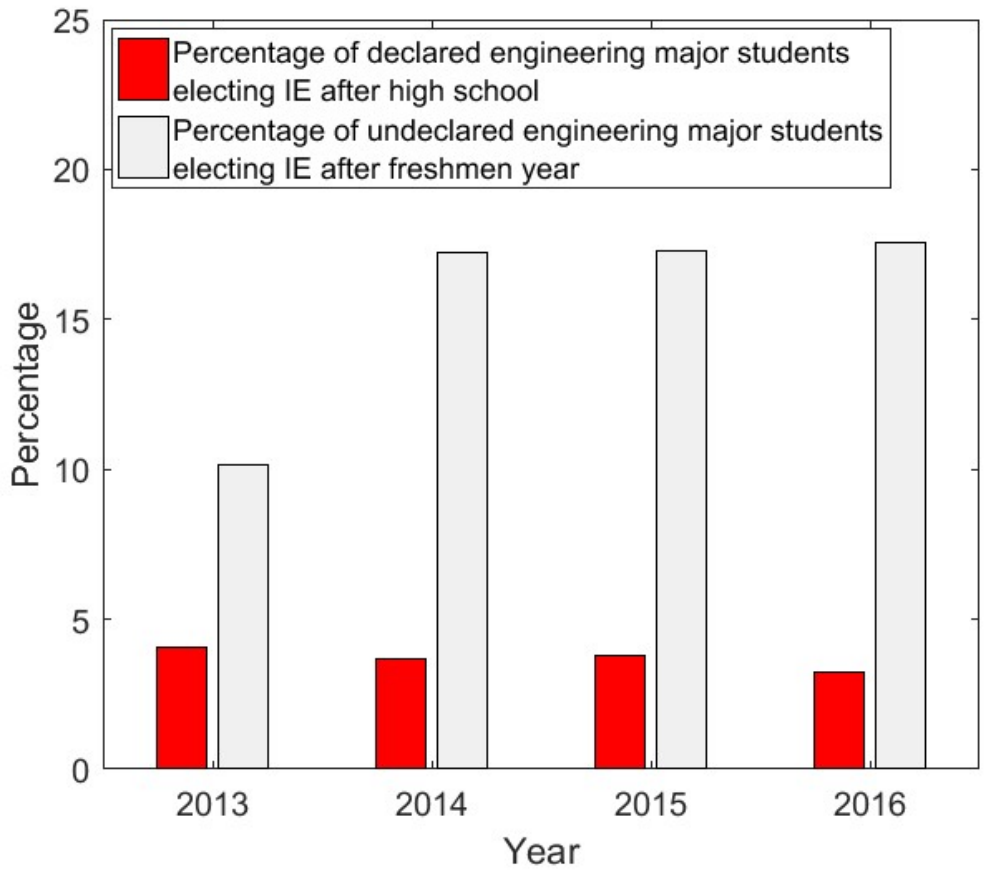

Figure 1: Percentage of high school graduates' vs undeclared freshmen choosing to major in IE.

Previous research has shown that K-12 students' awareness of a STEM discipline impacts their eventual selection of that discipline as a career option [2]. Existing literature on engineering outreach programs for the K-12 community suggests that the number of such programs focused on IE are significantly less than those for other disciplines [3-6]. Instead, most engineering outreach programs focus either on the engineering design process, or on mechanical, civil, electrical, or aerospace engineering. Therefore, for IE to live up to its potential as a discipline, a greater number of IE-oriented outreach activities are needed for the K-12 community.

Adopting an appropriate structure for IE outreach activities is important. These activities should highlight the impact of IE discipline on the society and business and clearly distinguish it from other engineering disciplines. The activities should be designed to develop a structured thought process among the students to help them solve challenging problems and then relate these 
activities to IE. However, previous research identified that the existing 'Engineering is Elementary' modules related to environmental engineering, agricultural engineering, and bioengineering are richer in science content than those based on industrial engineering [7]. Furthermore, because IE techniques are relevant for a wide variety of applications, a possible risk in IE outreach activities is that they may lead to a trivialization of the discipline. In particular, over-simplifying the activities may create misconceptions and undermine the contribution to the field.

To address these concerns, the IE activities described in this paper were designed to include a stronger math/science link, along with traditional IE concepts, such as line balancing, eliminating bottlenecks, and demand forecasting. This paper describes the development, deployment, and assessment of two different IE outreach activities conducted for the K-12 community at Iowa State University. The first activity uses Legos to simulate an assembly line in a manufacturing plant. The second activity aims to demonstrate supply chain management concepts using Hershey's Kisses. These activities introduce the students to the core definition of Industrial and Systems Engineering per the Institute of Industrial and Systems Engineers (IISE). The activities were conducted with pre-service teachers enrolled in the School of Education at Iowa State University, and with middle and high school students. The activities were designed to encourage self-learning among the students, followed by an exchange of theoretical concepts between the instructors and students.

The literature recommends discussing technical concepts with the students up-front before conducting the activity ('conventional structure'), and this was the approach that was used for the first activity. However, IE technical concepts are generally derivations of structural thinking and therefore tend to be more intuitive than the technical concepts from other engineering disciplines. Therefore, in the second activity IE concepts were discussed with the students at the end of the activities ('proposed structure').

\section{Design and Implementation of IE Outreach Activities}

Assembly line activity with Legos

In this activity, the students were introduced to the concept of an assembly line and the role of an industrial engineer in a manufacturing plant. The inspiration for this activity came from a firsthand experience with assembly line workers at a global appliance manufacturing company with facilities in the upper Midwest. The lead author was employed at this facility helping workers understand the benefits of lean manufacturing to increase operational efficiencies. We later discovered that a similar approach had been used with students using the 'conventional structure' [8]. However, the activities described in this paper were designed to use computer tools and provide the full flavor of the IE profession to the students, while also making them comfortable with the process.

Audience - The activity was first conducted as part of a short course on industrial, chemical, and civil engineering education developed for pre-service teachers enrolled in the College of Education at Iowa State University. This outreach effort was as result of a collaborative partnership formed between College of Engineering and College of Education faculty at Iowa 
State University [9]. To the best of our knowledge, this is the first outreach effort having a strong focus on IE with pre-service teachers. This activity was then conducted with high school students who participated in a summer camp organized by the Society of Women Engineers (SWE) at Iowa State University.

Description - The activity was conducted with two teams of five members each. At the beginning of the activity, a scenario about a toy manufacturing company that wanted to build toys for children in a relief camp was described to the participants. This social context was intended to help motivate participants to solve the problem. Figure 2 shows the Legos that were required to build a single toy, and Figure 3 shows the front and rear view of the finished toy, a sample of which was shared with each team.

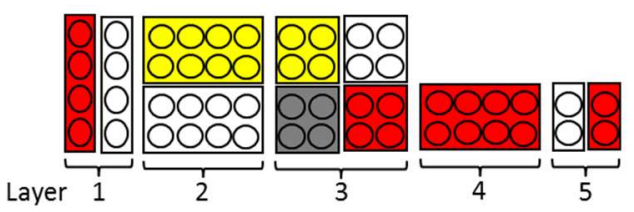

Figure 2: Legos used to build the toy.

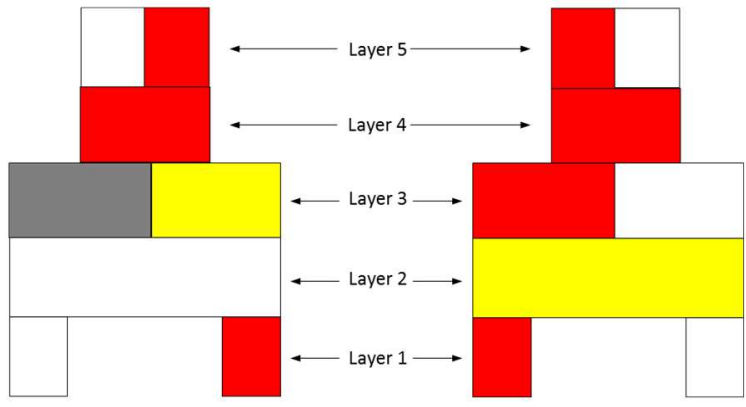

Figure 3: Front and rear views of the finished toy.

Table 1 describes three final product specifications. The participants were told that violating any of these would render the toy defective and useless to the manufacturing company.

Table 1: Product specifications for manufacturing the toy

\begin{tabular}{ll}
\hline Constraint & Description \\
\hline $\begin{array}{l}\text { Specification \# 1 - Correct } \\
\text { placement of Legos }\end{array}$ & $\begin{array}{l}\text { Each layer should have the same number of Legos as } \\
\text { given in the sample toy }\end{array}$ \\
$\begin{array}{l}\text { Specification \# 2-Match } \\
\text { color sequencing }\end{array}$ & $\begin{array}{l}\text { Two white Legos (on the top and the bottommost layer) } \\
\text { should be on the same side. Similarly, the two red Legos } \\
\text { (on the top and the bottommost layer) should be on the } \\
\text { same side (refer Figure 4) }\end{array}$ \\
$\begin{array}{l}\text { Specification \# 3-Match } \\
\text { color sequencing }\end{array}$ & $\begin{array}{l}\text { The yellow and gray square Legos as well as red and } \\
\text { white square Legos on the third layer should be adjacent } \\
\text { to each other (refer Figure 5) }\end{array}$ \\
\hline
\end{tabular}




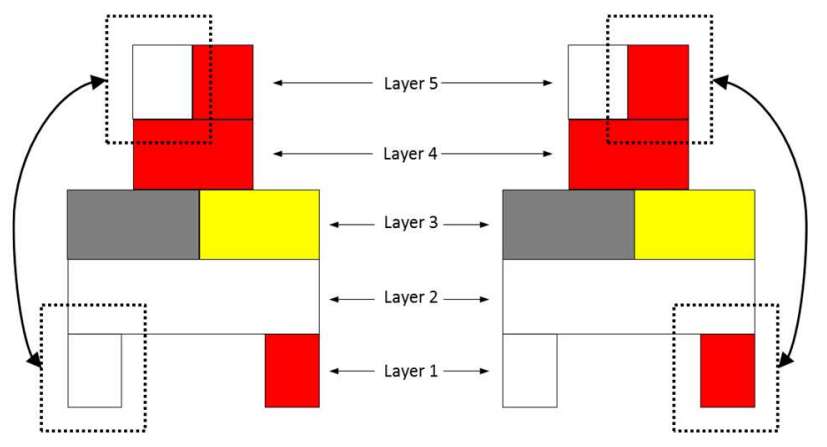

Figure 4: Specification \# 2.

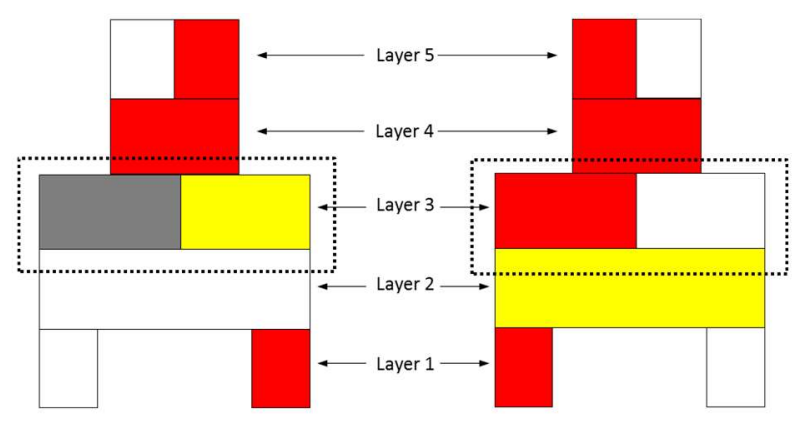

Figure 5: Specification \# 3.

Each team was given a set of Legos to create a set of 12 finished toys. The teams competed to produce the maximum number of error-free toys, subject to a 90 -second time limit. The activity was divided in three stages, with each stage introducing a different IE concept, as described below:

Stage 1: Each team was given a bag of Legos containing 12 sets of Legos required to make the toy, such that each team could produce a maximum of 12 finished toys. In addition, Legos of other shapes and sizes, which were not required for building the toy, were intentionally included in the bag. At the end of Stage 1, a lean manufacturing technique known as " $5 \mathrm{~S}$ " and a stationbased assembly line approach to manufacturing products were discussed with the teams.

Stage 2: Each team member was assigned to one of five workstations to create an assembly line. After assembly was completed at one workstation, the unit was passed on to the next station until the final product was completed at the fifth station (see Figure 6). At the end of Stage 2, a batch assembly line concept was discussed with the teams to demonstrate its usefulness for certain applications, such as the bakery industry.

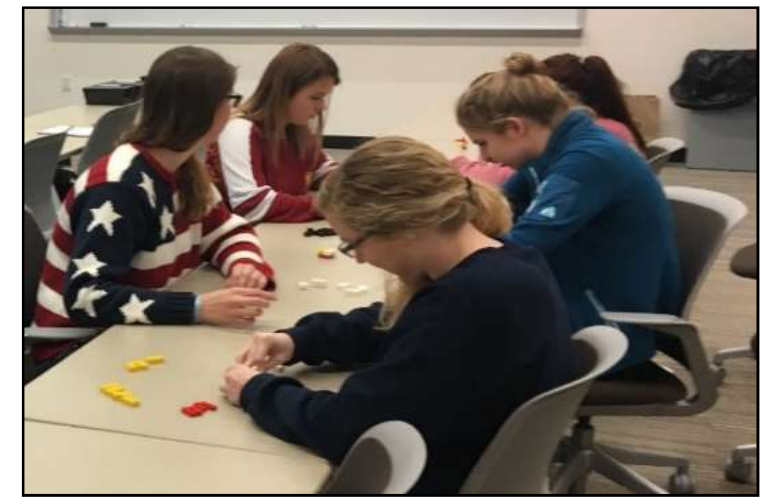

Figure 6: Preservice teachers simulating an assembly line to build toys.

Stage 3: The five-workstation assembly line then repeated the activity described in Stage 2. However, this time the participants were only allowed to move sub-assemblies to the next station in batches of four.

The outcomes of the three stages are shown in Table 2, which shows that Team 1 consistently improved its performance with each stage. After conducting the activity, several real-world examples of assembly lines were discussed with the participants, using videos and pictures. 
These examples were correlated with the activity to demonstrate how industrial engineers design the assembly lines to achieve maximum output using minimum resources and time.

Table 2: Outcomes of the three stages

\begin{tabular}{cccc}
\hline Stage & Team \# & $\begin{array}{c}\text { Number of } \\
\text { finished toys }\end{array}$ & $\begin{array}{c}\text { Number of } \\
\text { defective toys }\end{array}$ \\
\hline \multirow{2}{*}{ Stage 1} & 1 & 11 & 3 \\
& 2 & 5 & 0 \\
\multirow{2}{*}{ Stage 2} & 1 & 12 & 1 \\
& 2 & 12 & 0 \\
\multirow{2}{*}{ Stage 3 } & 1 & 12 & 0 \\
& 2 & 11 & 0 \\
\hline
\end{tabular}

The importance of data analysis was also discussed to emphasize the role of quantifying and effectively communicating engineering results. Participants were shown how industrial engineers plot graphs and figures using Microsoft Excel, allowing them to visualize results, present them to senior management, and support decision-making. Feedback from one participant's post-activity survey is in the text box below. Details on time and cost requirements to conduct this activity can be found from the URL in reference [10].

"I think as many different experiments or interactions with as many different engineering processes would be best! I loved that we focused on the civil engineering and chemical (banana bread), and industrial (Legos). I think the more we expanded it, the better understanding we could gather from the broader sense of engineering and the specifics on the various roles within engineering."

Observations and Discussion - When this activity was conducted with high school students using the 'conventional structure' described above, it was observed that some students created an assembly line structure by themselves to build toys in Stage 1 (see figures 7 and 8). However, when asked, none of the teams knew about the concept of an assembly line.

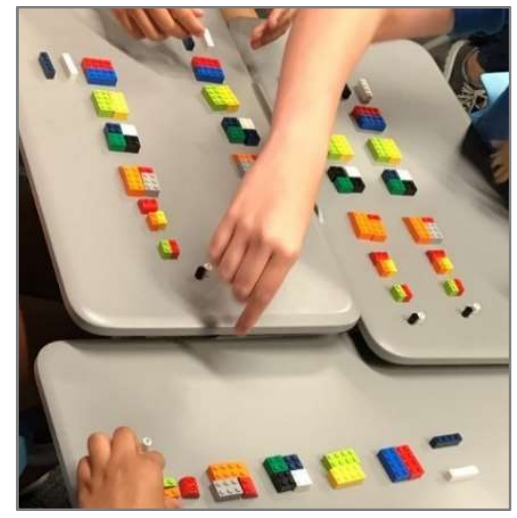

Figure 7: Team 1 assembly line structure.

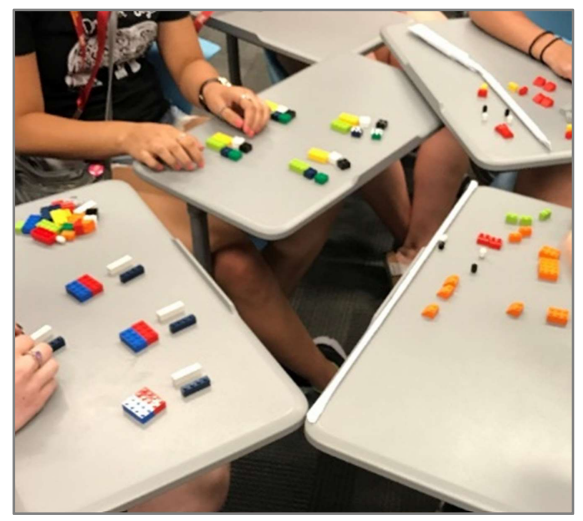

Figure 8: Team 2 assembly line structure. 
This observation led the authors to reevaluate the structure of this activity, in which the theoretical concepts were demonstrated up-front to the teams. The authors believe that having students develop their own assembly line and brainstorm ideas to improve the system efficiency in each iteration would be more effective in illustrating the importance of the IE field. Further, the thought process of the students behind improving the system could be connected to IE technical terminology. This would allow the activity to become more interesting for students and instill confidence in them when they realize that they were already engaged in the industrial engineering process, albeit at a simple level.

A very common misconception among K-12 students, which is also a major reason for low enrollment in STEM fields, is the perceived difficulty in pursuing a career in this field [11]. Having students come up with their own ideas for system improvement, and thereafter discussing the theory and the underlying principles of IE using the same context ('proposed structure'), could encourage them to view IE as an approachable field.

Reflections from the IISE definition - IISE defines Industrial and Systems Engineering as "A discipline concerned with the design, improvement and installation of integrated systems of people, materials, information, equipment and energy. It draws upon specialized knowledge and skill in the mathematical, physical, and social sciences together with the principles and methods of engineering analysis and design, to specify, predict, and evaluate the results to be obtained from such systems." Per this definition of IE, this activity addresses the idea of designing a system consisting of materials and people, improving the system to make it more efficient, and incorporating methods of engineering analysis.

Data analysis and communication skills - Through this activity, students develop skills in math by collecting, recording, and analyzing data, as well as in effective communication by drawing and interpreting graphs. By redesigning the assembly line to improve the system efficiency, this activity helps impart scientific thinking to students by teaching them to hypothesize, perform experiments, and observe results.

\section{Supply Chain Management Activity with Hershey's Kisses}

The second activity used concepts of demand forecasting and supply chain management to introduce students to the field of IE. This was an original activity developed by the authors - we were unable to find a similar activity described in the literature. A 'proposed structure' was used in this activity, allowing students to find creative ways of improving their performance in each iteration and then discussing the relevant underlying IE principles after the activity was completed.

Audience - The activity was primarily conducted with female middle school students who attended a STEM camp organized by the Program for Women in Science and Engineering at Iowa State University.

Description - The activity started with a discussion about how the candies are made and how the ingredients are sourced. The students were encouraged to think about the production process 
from beginning to end, including raw material production, transportation and logistics, manufacturing, and delivery to retailers and consumers.

After setting the context, the students were divided into teams of 4-5. Each team took on the role of retail store management. First, the teams were instructed to decide how many Hershey's Kisses they wanted to order to fulfill customer demand over the next five weeks. The candies could be sourced either from Iowa or California or both. The cost of purchasing one unit from California was $\$ 1$, whereas the Iowa supplier charged $\$ 5$ per unit (see sample worksheet in Figure 9). However, the shipping cost from California (\$100) was greater than from Iowa (\$50). While the costs were fixed and known, there was uncertainty around the delivery times from both suppliers. The shipment from Iowa could arrive in one or two weeks, whereas the shipment from California could arrive in one, two, or three weeks. After each team decided on the quantities they wanted to purchase from each supplier, they were asked to draw a card from a deck of index cards (i.e., randomly) to determine the arrival weeks (one, two, or three) of their shipments.

\begin{tabular}{|c|c|c|c|c|c|}
\hline \multicolumn{3}{|c|}{ Material Cost } & \multicolumn{3}{|c|}{ Shipping Cost } \\
\hline & \multicolumn{2}{|c|}{ Kisses } & & lowa & California \\
\hline & lowa & California & $\begin{array}{c}\text { Number of Shipments: } \\
0 \text { or } 1\end{array}$ & & \\
\hline $\begin{array}{l}\text { Inventory Quantity } \\
\text { (your decision) }\end{array}$ & & & $\begin{array}{c}\text { Arrival Week } \\
\text { (draw card) }\end{array}$ & & \\
\hline Unit Cost & $\$ 5.00$ & $\$ 1.00$ & Cost per Shipment & $\$ 50$ & $\$ 100$ \\
\hline $\begin{array}{c}\text { Material Cost } \\
\text { (Quantity x Unit Cost) }\end{array}$ & & & $\begin{array}{c}\text { Shipping Cost } \\
\text { (\# of Shipments } \times \text { Cost) }\end{array}$ & & \\
\hline Total Material Cost & & & Total Shipping Cost & & \\
\hline \multicolumn{3}{|c|}{ Delivery to Customer Cost } & \multicolumn{3}{|c|}{ Revenue } \\
\hline \# Delivery in Week & 0 or $\$ 20)$ & & & $\begin{array}{c}\text { Demand } \\
\text { (Draw card) }\end{array}$ & $\begin{array}{c}\text { Revenue } \\
\text { (Demand } x \$ 20)\end{array}$ \\
\hline \# Delivery in Week & 0 or $\$ 20)$ & & Week 1 & & \\
\hline \# Delivery in Week & 0 or $\$ 20)$ & & Week 2 & & \\
\hline \# Delivery in Week & 0 or $\$ 20)$ & & Week 3 & & \\
\hline \# Delivery in Week & 0 or $\$ 20)$ & & Week 4 & & \\
\hline \multirow[t]{2}{*}{ Total Delivery Cost } & & & Week 5 & & \\
\hline & & & \multicolumn{2}{|r|}{ Total Revenue } & \\
\hline Profit $=$ & I Reven & terial Co & ipping Cost - Total De & & \\
\hline
\end{tabular}

Figure 9: Sample worksheet used in the Hershey's Kisses supply chain activity. 
The instructors then handed out the "shipments" (i.e., Hershey's Kisses) to each team that expected a delivery in the week one, and these were placed into "inventory". Each team was then asked to draw a card from another deck of demand cards to determine the customer demand for week one. The teams would satisfy as much demand as possible, given their current inventory levels. Each unit of demand that the team was able to fulfill would earn them $\$ 20$ in revenue. The teams were then informed that they would incur a $\$ 20$ cost to transport customer orders each week. This process was repeated for five simulated weeks. The net profit at the end of week five was calculated using the profit equation shown in Figure 9.

After each team calculated its net profit, the students were asked why they thought they made loss or profit and what strategy they could have adopted to increase their profit. The activity was then repeated, giving the students a chance to improve their performance. At the end of the activity, a real-world example was discussed with the students to explain how industrial engineers help stores to maximize their profits by forecasting demand for millions of items and calculating appropriate inventory levels. Figure 10 shows a snapshot of a student team that participated in the activity.

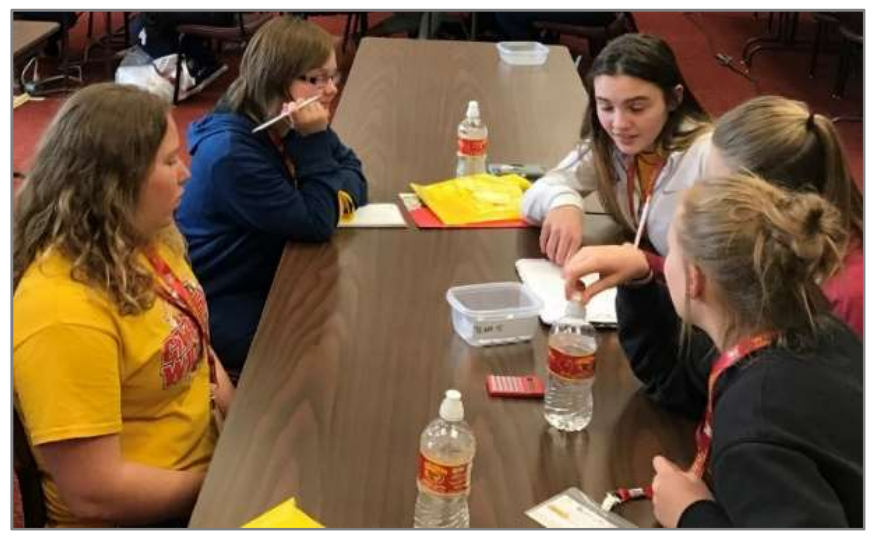

Figure 10: Middle school students working to maximize their store's profit.

The text box below includes participants feedback from a post-activity survey. Details on time and cost for conducting the activity can be found from the URL in reference [10].

"This session was lots of fun. I got to meet girls from other schools because of the activity. I also liked the hands-on learning aspect of it."

"It was good it taught you how to make profits."

"I certainly love love LOVED it when we ran our own company and making a profit of money to keep it running. The activity was really fun."

"There was a lot of participation to the questions asked and there was a good amount of hands on Stuff." 
Observations and Discussion - Some teams were profitable in the first round of the activity. Many student groups were never profitable but were able to reduce their losses significantly in the second round. In the second round, it was observed that many of the students had learned the value of planning, forecasting, and managing risk when determining the size and source of inventory replenishment orders. To this end, they applied logic and math in an effort to improve their decision-making. For example, one team purchased their entire inventory from California in the first round, which helped them reduce their total material cost. However, the late arrival of the shipment in the third week prevented them from satisfying customer demand in weeks one and two. As a result, at the end of the week five, the team was left with a large amount of unsold stock. This experience taught them about tradeoffs and risks associated with relying on a single supplier.

Reflections from the IISE definition - Per the definition, the concepts that were targeted through this activity were specifying, predicting, and evaluating the results from a system, and achieving improvement by analyzing past performance.

Math skills - Math skills developed through this activity include collecting, recording, and analyzing data, evaluating revenue, profit, and loss, and algebraic reasoning.

\section{Conclusion}

More outreach activities should be developed to help familiarize the K-12 community with the IE discipline. This paper describes two IE outreach activities that were conducted with preservice teachers in the College of Education at Iowa State University, as well as middle school and high school students. Future work includes a quantitative assessment of the impact of 'conventional' and 'proposed' structures in these two outreach activities on increasing the K-12 community's understanding of the IE discipline. The activities could also be further developed to demonstrate how industrial engineers build computer models to study and improve the efficiency of large-scale and complex production systems, such as an automotive assembly line.

It is hoped that this paper will inspire industrial engineers to develop additional age-appropriate outreach activities to familiarize students with the IE discipline and encourage them to pursue IE degrees after high school graduation.

\section{References}

[1] Darwish, H., \& Van Dyk, L. (2016). The Industrial Engineering Identity: From Historic Skills to Modern Values, Duties, and Roles. South African Journal of Industrial Engineering, 27(3), 50-63.

[2] Ozis, F., Pektas, A. O., Akca, M., \& DeVoss, D. A. (2017). How to Shape Attitudes Towards STEM Careers: The Search for the Most Impactful Extracurricular Clubs (RTP). Proceedings of the American Society of Engineering Education Annual Conference, Columbus, $\mathrm{OH}$.

[3] Brophy, S., Klein, S., Portsmore, M., \& Rogers, C. (2008). Advancing Engineering Education in P-12 Classrooms. Journal of Engineering Education, 97(3), 369-387. 
[4] Carr, R. L., Bennett, L. D., \& Strobel, J. (2012). Engineering in the K-12 STEM Standards of the 50 US States: An Analysis of Presence and Extent. Journal of Engineering Education, 101(3), 539-564.

[5] Jeffers, A. T., Safferman, A. G., \& Safferman, S. I. (2004). Understanding K-12 Engineering Outreach Programs. Journal of Professional Issues in Engineering Education and Practice, 130(2), 95-108.

[6] Mendoza Díaz, N. V., \& Cox, M. F. (2012). An Overview of the Literature: Research in P-12 Engineering Education. Advances in Engineering Education, 3(2).

[7] Council, N. R. (2009). Engineering in K-12 Education: Understanding the Status and Improving the Prospects. National Academies Press.

[8] Whitman, L. E., \& Witherspoon, T. L. (2003). Using LEGOs to Interest High School Students and Improve K12 Stem Education. Change, 87(76).

[9] Tank, K. M., Raman, D. R., Lamm, M. H., Sundararajan, S., \& Estapa., A. T. (2017). Teaching Educators About Engineering: Preservice Elementary Teachers Learn Engineering Principles from Engineers. Science and Children, 54(1), 84-89.

[10] Digital Repository, Iowa State University (2018). Accessible at http://works.bepress.com/anuj-mittal/12/.

[11] Hossain, M., \& G Robinson, M. (2012). How to Motivate US Students to Pursue STEM (Science, Technology, Engineering and Mathematics) Careers. Retrieved from https://files.eric.ed.gov/fulltext/ED533548.pdf.

\section{Acknowledgments}

The material presented here is based upon work supported by the National Science Foundation under Award No. DRL-1440446 Teachers and Engineers Collaborating in STEM Elementary Teacher Preparation. Any opinions, findings, and conclusions or recommendations expressed in this material are those of the authors and do not necessarily reflect the views of the National Science Foundation, nor of Iowa State University. The authors also thank other project members and cooperating faculty for their support, including Dr. Monica H. Lamm, Dr. Kristina M. Tank, Dr. Anne T. Estapa, Dr. Adah Leshem, Dr. Joanne K. Olson, Dr. Rohit Mehta, Dr. Mollie H. Appelgate, and Jennifer Lillo. Special thanks to Program for Women in Science and Education at Iowa State University for allowing the authors to conduct IE outreach activities with female middle school students. 